\title{
LONG-LIVED METEOR TRAILS
}

\section{A.V. Mikhalev}

Institute of Solar-Terrestrial Physics SB RAS

Irkutsk,Russia,mikhalev@iszf.irk.ru

\section{A.B. Beletsky}

Institute of Solar-Terrestrial Physics SB RAS

Irkutsk,Russia,beletsky@iszf.irk.ru

R.V. Vasilyev

Institute of Solar-Terrestrial Physics SB RAS

Irkutsk,Russia,roman_vasilyev@iszf.irk.ru

\section{M.V. Eselevich}

Institute of Solar-Terrestrial Physics SB RAS

Irkutsk,Russia,mesel@iszf.irk.ru

\section{K.I. Ivanov}

Irkutsk State University

Irkutsk,Russia,ivorypalace@gmail.com

\section{E.S. Komarova}

Irkutsk State University

Irkutsk,Russia,eskomarik@gmail.com

\section{A.V. Podlesnyi}

Institute of Solar-Terrestrial Physics SB RAS

Irkutsk,Russia,pav1986@rambler.ru

S.V. Podlesny

Institute of Solar-Terrestrial Physics SB RAS

Irkutsk,Russia,step8907@mail.ru

T.E. Syrenova

Institute of Solar-Terrestrial Physics SB RAS

Irkutsk,Russia,angata@iszf.irk.ru
Abstract. The paper presents data on long-lived ( 20-40 min) meteor trails. We describe a group of soliton-type meteor trails expanding at transonic speeds. Radio sounding data evidences that the latter include $\sim 7$ 8 min ionization trails. We also consider one event with an ordinary shape and dynamics of meteor trails. These ordinary meteor trails are formed due to wind flows at heights of meteor glow.

We describe the space-time structure of the detected meteor trails. In particular, in the November 18, 2017 event the typical size of the expanding trail area reached approximately $400 \mathrm{~km}$ and retained its semioval shape. The meteor trail propagated mainly in the horizontal plane at heights of $\sim 86-91 \mathrm{~km}$.

We examine possible mechanisms of long-lived meteor trails propagating at transonic speeds. We estimate speed variations of meteor particles of size from $1 \mu \mathrm{m}$ to $10 \mathrm{~mm}$ for $\sim 70-120 \mathrm{~km}$ heights during their horizontal motion. It is shown that the mode of meteor particle motion without deceleration on the typical timescale of $\sim 10^{3} \mathrm{~s}$ at $70-90 \mathrm{~km}$ heights can be realized only for large particles over $100 \mu \mathrm{m}$. Mechanisms and spectral composition of long-lived meteor trail glow are discussed.

Keywords: long-lived meteor trail, ionization meteor trail, meteor trail glow, airglow.

\section{INTRODUCTION}

Over many years, reports have regularly emerged in the literature about meteor trails with lifetimes as long as tens of minutes. This phenomenon usually occurs during the impact of strong meteor showers, such as the Leonids meteor shower, on Earth's atmosphere [Clemesha et al., 2001]. The articles dealing with this phenomenon in the optical range focus on the processes that cause a long-term meteor trail glow [Kelley et al., 2000]. Meanwhile, this phenomenon is of great interest for diagnostics of the state of Earth's upper atmosphere and ionosphere. Most such works rely on radar observations of ionization meteor trails whose duration can sometimes be as long as several minutes [Kashcheev et al., 1967]. It is known that the passage of artificial and natural space objects such as meteoroids, spacecraft, and their fragments in the upper atmosphere may be accompanied by a number of phenomena such as shock and acoustic gravity waves (AGW), medium heating and ionization at the mesosphere-lower thermosphere heights [Grigoryev, 1999; Silber et al., 2018], which in some cases cause airglow disturbances in the optical range [Avakyan et al., 1991; Beletsky et al., 2004; Mikhalev, 2011]. There are a fairly large number of papers with results of studies of waves, wave structures, and disturbances during AGW propagation at heights of the upper atmosphere from the data on variations in ionospheric parameters or on recording of infrasound on the ground surface. At the same time, optical imaging of waves or their manifestations that occur when meteors enter the upper atmosphere or explode in it, has been described in few publications (see, e.g., [Avakyan et al., 1991]). The literature deals mainly with meteor trails formed along the meteor trajectory (trajectory meteor trails), which are further transformed and displaced by the impact of turbulent motions and regular winds at heights of meteor burning. Mechanisms and peculiarities of the kinetics of meteor trails have been discussed in many papers (see, e.g., [Kashcheev et al., 1967; Bronstein, 1981; Smirnov, 1994]), but in most cases they also deal with the trajectory meteor trails.

Mikhalev et al. [2018] have reported on registration of long-lived ( 20-40 min) unusually shaped meteor 
trails expanding at transonic speeds. The purpose of this work is to present in more detail the results of recording of long-lived meteor trails (LMT) and to discuss possible conditions and mechanisms for their formation.

\section{EQUIPMENT AND OBSERVATIONAL METHOD}

Airglow observations are made at the ISTP SB RAS Geophysical Observatory $(\mathrm{GPhO})\left(52^{\circ} \mathrm{N}, 103^{\circ} \mathrm{E}\right)$, located in the Tunka valley (the village of Tory) in the south of Eastern Siberia. The complex of optical and radiophysical instruments installed in GPhO includes spectrographs, wide-angle color and monochromatic cameras, and ionosonde. All these instruments operate fully in automatic mode. In this study, we have used observations made with an all-sky camera KEO Sentinel, wide-angle camera in the $557.7 \mathrm{~nm}$ emission, spectrographs SATI-1M and SATI-2, color wide-angle camera, as well as data acquired by an ionosonde of vertical and oblique sounding of the ionosphere by chirp signals (Ionosonde-MS).

The all-sky camera KEO Sentinel is designed to record the spatiotemporal dynamics of $630 \mathrm{~nm}$ emission intensity (180-300 km spontaneous emission heights). The half-width of the interference filter is $\sim 2 \mathrm{~nm}$. The viewing direction is zenith, the field of view is $145^{\circ}$, the exposure time is $60 \mathrm{~s}$ [http://atmos.iszf.irk.ru/ru/data/keo].

The color wide-angle high-sensitivity camera Filin$1 \mathrm{Ts}$ comprises a cooled color CCD matrix KODAK KAI-11002. As the entrance lens we use the Mir-20 lens (20 mm focal length, 1:3.5 focal ratio). The camera has a thermostable case, a rotating turret, and is pointed at the northern sky, at the celestial pole. The camera angular field of view is $\sim 90^{\circ}$, exposure time is $300 \mathrm{~s}$ [http://atmos.iszf.irk.ru/ru/data/color].

In addition, we have used observations from the color all-sky camera installed in ISTP SB RAS Sayan Solar Observatory (SSO) near the village of Mondy $\left(51.6^{\circ} \mathrm{N}\right.$, $\left.100.9^{\circ} \mathrm{E}\right)$. SSO is located $150 \mathrm{~km}$ to the west of GPhO. For the observations we employed the AllSky-340 camera with a $640 \times 480$ CCD receiver Kodak KAI-340. The camera has a fisheye lens with a focal length of $4 \mathrm{~mm}$ and a focal ratio of 1:4, which ensures an angular field of view of $185^{\circ} \times 145^{\circ}$. The scale of image in zenith is $18 \mathrm{arcmin} /$ pix. The typical exposure in the nighttime is $60 \mathrm{~s}$, the interval between successive frames is $140 \mathrm{~s}$.

The spectrographs are designed to record nightglow spectra (mostly of dominant emissions in the nightglow spectrum - atomic oxygen [OI] 557.7, $630.0 \mathrm{~nm}$ and sodium doublet $\mathrm{Na}$ [OI] 589.0-589.6 nm) in studies of processes in the upper atmosphere during heliogeophysical disturbances of different nature. The spectrographs are described on the websites [http://atmos.iszf.irk.ru/ru/ data/spectr] (SATI-1M) and [http://atmos.iszf.irk.ru/ru/ data/sati2] (SATI -2).

The Fabry-Perot interferometer is designed to measure atmospheric temperature and wind speed in an altitude range $80-300 \mathrm{~km}$. The measurement technique rests on recording the Doppler shift and Doppler broadening of nightglow lines. The observations are made at fixed wavelengths: 630, 557.7, 589.3, 427.8, 732.0,
$843.0 \mathrm{~nm}$ (oxygen, sodium, and nitrogen), thus providing a vertical profile of atmospheric parameters. During the observations, we scan a part of the celestial sphere to restore the complete wind velocity vector as well as to estimate the atmospheric temperature gradient in an area with linear dimensions of several hundred kilometers. This instrument is described on the website [http://atmos.iszf.irk.ru/ru/data/fpi].

The Ionosonde-MS operates in the chirp sounding network of ISTP SB RAS. Transmitters of the network are located near Usolye Sibirskoye (point Usolye), Norilsk, Khabarovsk, and Magadan. Besides receiving oblique and near-vertical sounding signals from the network transmitters, the Ionosonde-MS performs vertical ionospheric sounding every minute [http://dep1.iszf.irk.ru/CHIRP_ionogrames].

\section{OBSERVATIONAL RESULTS AND DISCUSSION}

November 16, 2017 event The long-lived meteor trail recorded on November 16, 2017 is a trail with ordinary shape and dynamics. Such a trail is developed from a linear meteor trail (along the meteor trajectory) under the action of wind flows at heights of meteor trail glow. Figure 1 shows fragments of images of meteor entry into Earth's atmosphere and LMT captured by the wide-angle color camera at GPhO near the northern horizon on November 16, 2017.

The mean velocity projection on the plane of the sky of the bow emission region motion in the linear ejection phase in the interval 21:43:02-21:58:00 UT (frames 25 ) is $\sim 21-24 \mathrm{~m} / \mathrm{s}$ (for the expected explosion height of $\sim 85 \mathrm{~km}$ ). After 21:58:00 UT, the developed structure moves at a characteristic velocity of $\sim 22 \mathrm{~m} / \mathrm{s}$ in the northwest direction, which coincides with the wind direction as derived from Fabry-Perot interferometer data in the $557.7 \mathrm{~nm}$ line.

Short-term IGWs, captured by the color camera Filin1Ts, propagated in the same direction. The observation of the meteor trail ended at 22:37:52 UT, hence the total observation time was $\sim 1 \mathrm{hr}$.

Figure 2 presents observations of intensity variations in the $589.0-589.6 \mathrm{~nm}$ Na line (doublet) made by the spectrograph SATI-2 (a), and fragments of images from Figure 1 separated by R-G-B color channels $(b)$. The spectrograph is pointed northward with $\sim 23^{\circ}$ optical axis elevation above the horizon.

Among the observed features of the $\mathrm{Na}$ emission intensity variations is an increase in signal dispersion shortly after the meteor explosion. The standard deviation changed from 11.02 to 15.75 when the mean value of $\sim 74$ was constant. In the R-G-B channels of the color camera, LMT was observed almost exclusively in the R and $\mathrm{G}$ channels.

The November 18, 2017, January 23, and November 12,2018 events are a group of soliton-type meteor trails.

November 18, 2017 event In Figure 3 are fragments of successive images taken by the all-sky camera KEO Sentinel near the western horizon on November 18, 2017; in Figure 4, successive images of the same event taken by the color camera at SSO. 

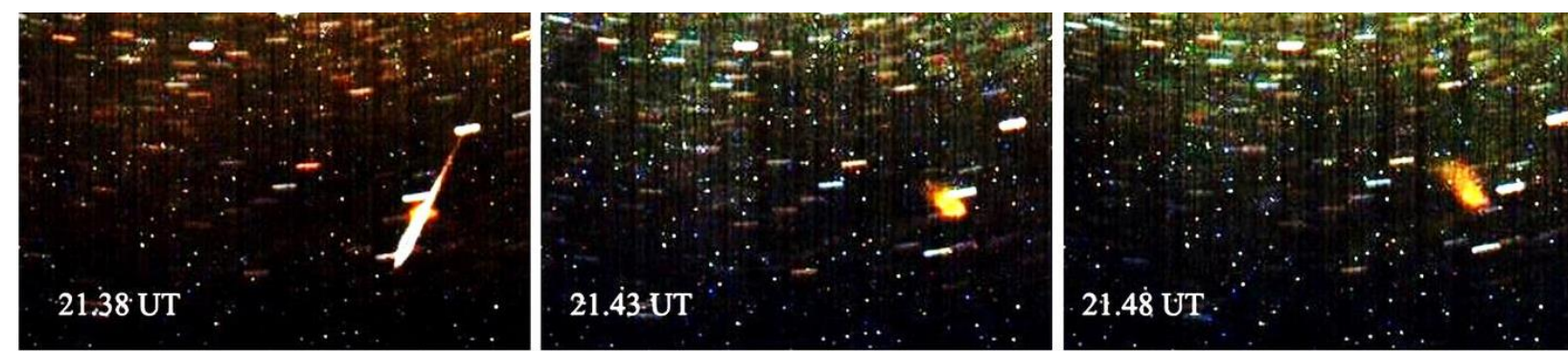

\section{$21.48 \mathrm{UT}$}
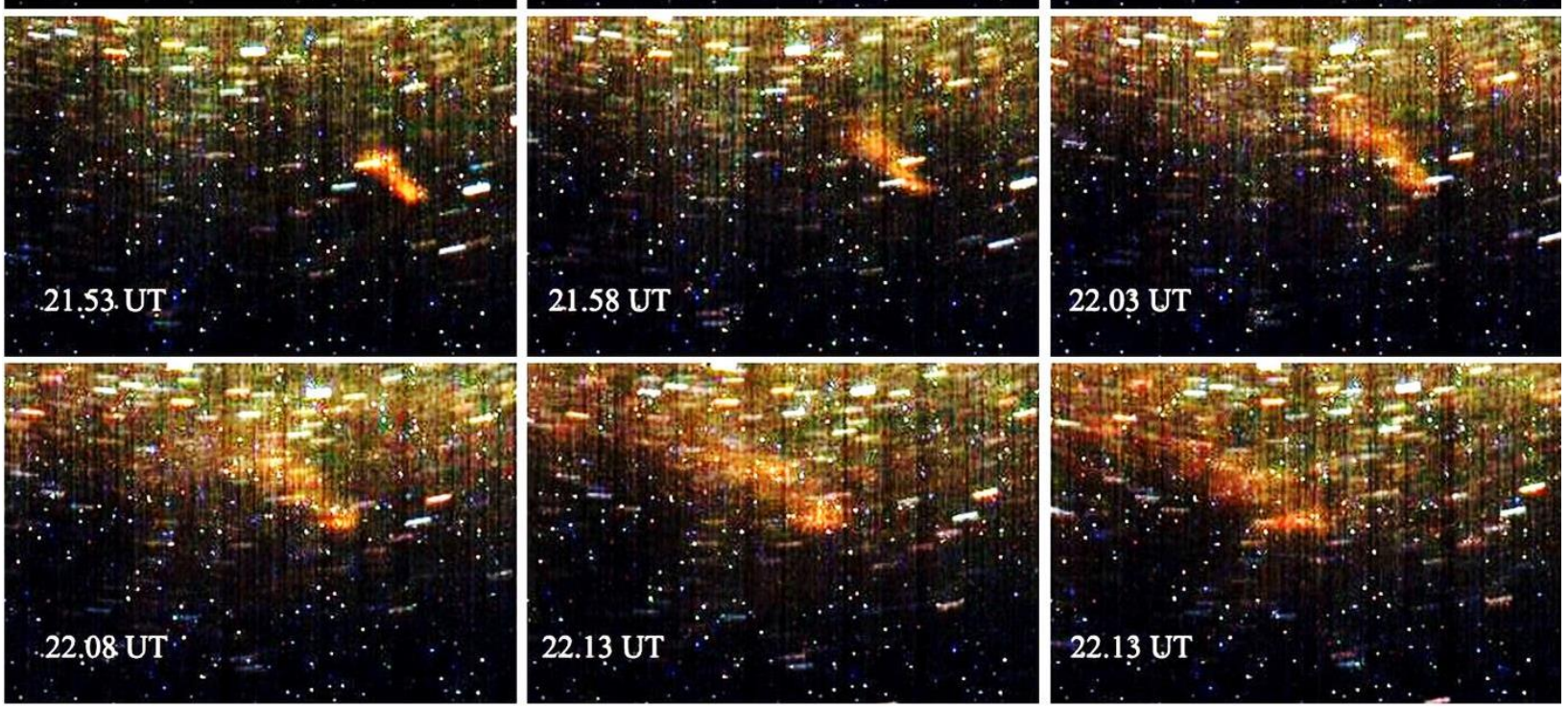

Figure 1. Fragments of images of meteor entry into Earth's atmosphere and a long-lived meteor trail recorded by a wideangle color camera on November 16, 2017. In the images is the frame recording time. The exposure time is $300 \mathrm{~s}$. Two bright trails from starts over the place of the formation of the long-lived meteor trail match the stars of the Cygnus constellation $\mathrm{k}$ Cyg and 1 Cyg with stellar magnitudes of 3.8 and 3.75 respectively
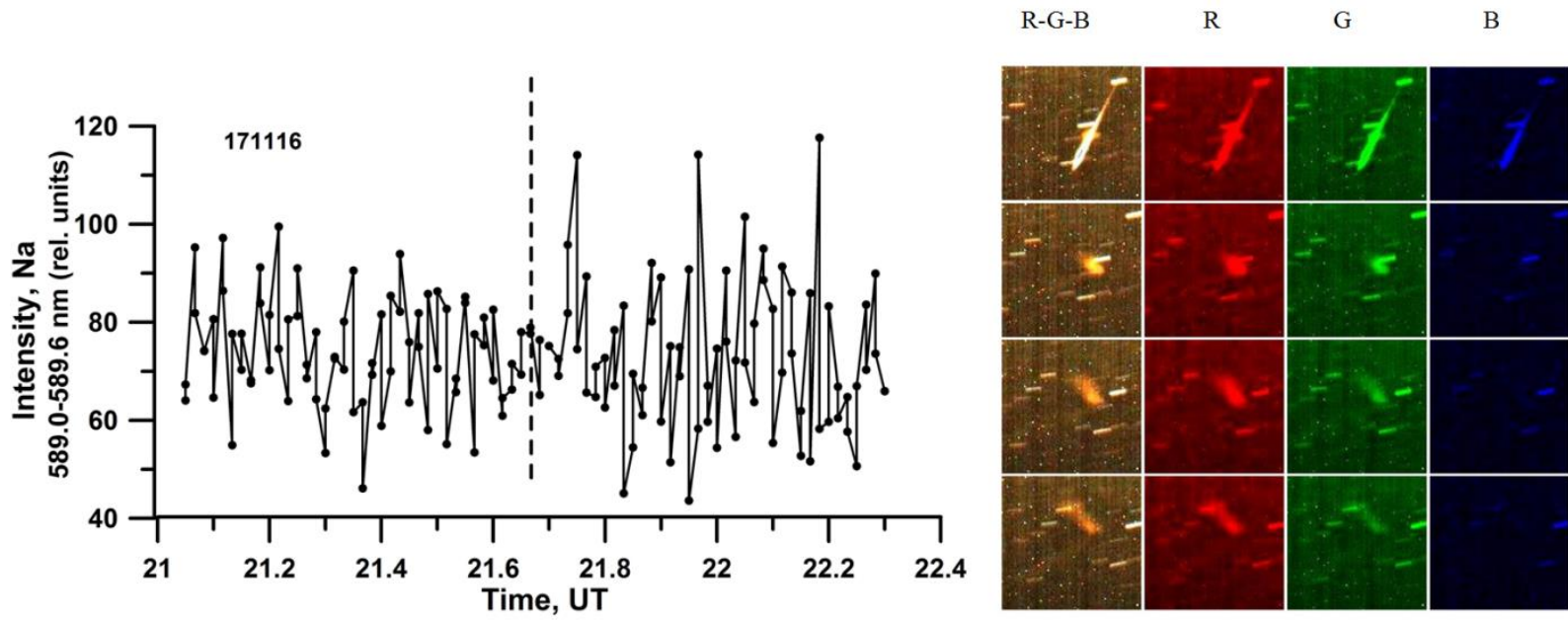

Figure 2. Variations in $589.0-589.6 \mathrm{~nm} \mathrm{Na}$ line intensities $(a)$ and fragments of images from Figure 1, separated by R-G-B color channels $(b)$. The vertical dashed line shows the meteor explosion time

Meteor observations made from two different directions ( $\mathrm{SSO}$ and $\mathrm{GPhO}$ ) allow us to determine the spatial position of individual parts of this phenomenon. The meteor trail was observed in adjacent frames obtained at SSO and $\mathrm{GPhO}$ at 22:23:19 and 22:23:29 UT respectively. Start and end of the spontaneous emission (determined from a noise level of $3 \sigma$ relative to the background) correspond to heights of $108.3 \pm 0.1$ and $72.2 \pm 0.1 \mathrm{~km}$. The minimum brightness in the meteor trail corresponds to a height of $82.2 \pm 0.3 \mathrm{~km}$. The visible length of the trail is $43.7 \mathrm{~km}$.

The meteor trail propagates mainly in the horizontal plane in the altitude range $86-91 \mathrm{~km}$. The source of the meteor trail is approximately localized at the maximum brightness of the trail in the vicinity of the first flash at a height of $87.8 \mathrm{~km}$. The bow region of the meteor trail loop in the interval 22:25-22:47 UT moves at a constant 

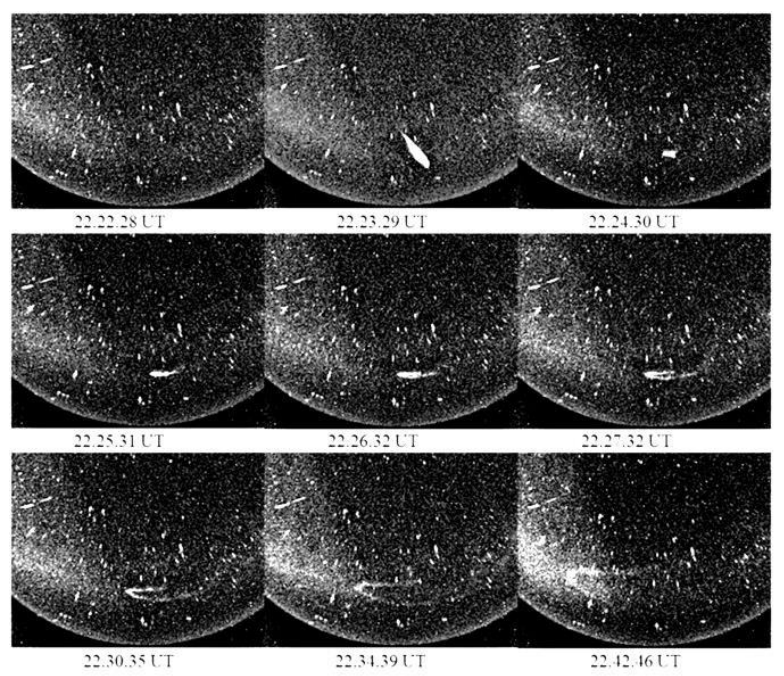

Figure 3. Fragments of images taken by the all-sky camera KEO Sentinel at GPhO near the western horizon on November 18,2017
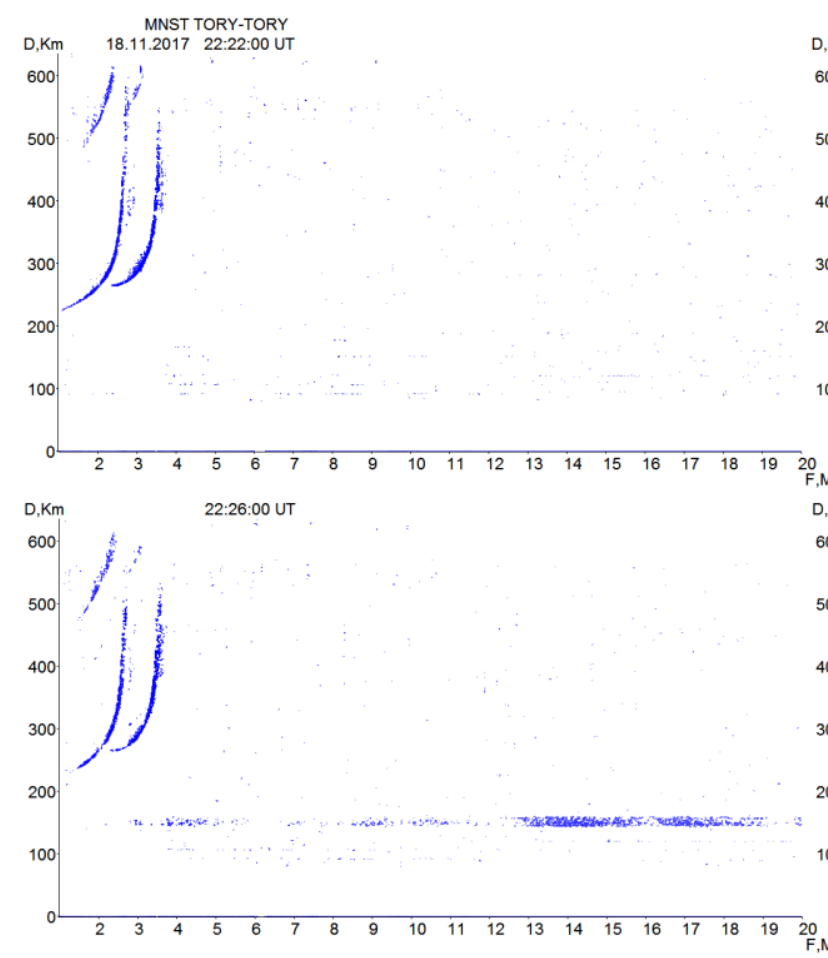
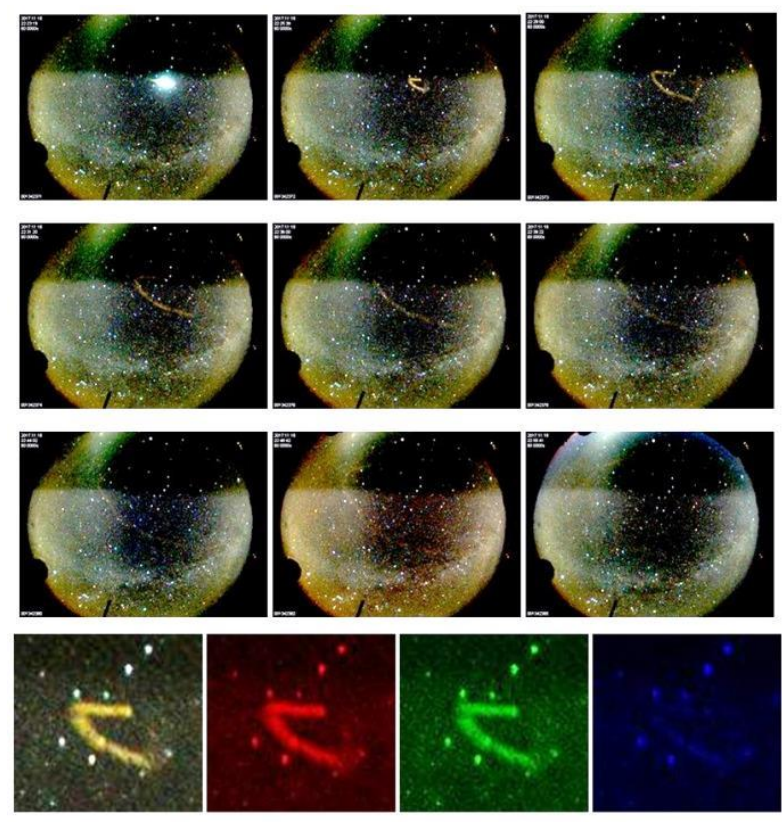

Figure 4. Successive images captured by a color camera at SSO on November 18, 2017 at the same time intervals as shown in Figure 3. Bottom row: enlarged fragments of color and R-G-B images for 22:25 UT
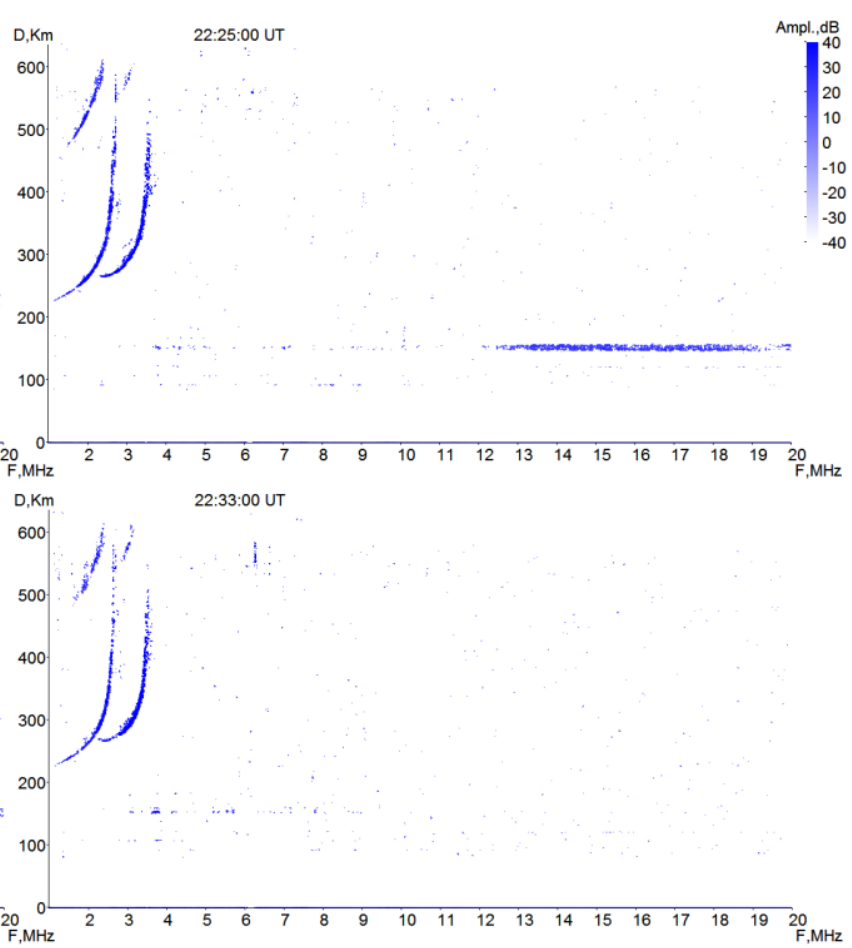

Figure 5. Vertical sounding ionograms obtained by the Ionosonde-MS on November 18, 2017

velocity of $\sim 320 \mathrm{~m} / \mathrm{s}$ and for the given time shifts by $\sim 400 \mathrm{~km}$. The total time of the meteor trail observation, as derived from optical data, is $\sim 35-40 \mathrm{~min}$.

Figure 5 shows vertical sounding ionograms obtained by the Ionosonde-MS. The sounding was carried out once per minute in a frequency range 1-20 $\mathrm{MHz}$ with a frequency-tuning rate of $1 \mathrm{MHz} / \mathrm{s}$. Reflections from the regular F2 layer with an apparent height of more than $200 \mathrm{~km}$ are pronounced. In panel (a) is an ionogram before the meteor impact; panels $(b, c)$ show characteristic horizontal trails of reflections from high-ionization regions with an apparent height of $\sim 150 \mathrm{~km}$ in two or three minutes after the impact, which are almost not visible in panel $(d)$ corresponding to $10 \mathrm{~min}$ after the impact.

The occurrence of the high-ionization region concurs with the main meteor flash according to optical data. This allows the preliminary identification of this region as an ionization LMT. The total time of its observation was $\sim 7-8 \mathrm{~min}$. Projections of the velocity of dif- 
ferent areas of the trail estimated from the upper and lower edges of horizontal trails in ionograms are $\sim 25$ $50 \mathrm{~m} / \mathrm{s}$, being significantly lower than the velocity of the optical trail. The characteristic size of the expanding ionization trail does not exceed $\sim 20-25 \mathrm{~km}$.

Figure 6 presents neutral wind data obtained by the Fabry-Perot interferometer in the $557.7 \mathrm{~nm}$ atomic oxygen [OI] line (85-115 km spontaneous emission heights).

We can see that during the LMT formation and development there was a predominantly northerly wind blowing at a speed of 60 to $80 \mathrm{~m} / \mathrm{s}$. Probably, this feature of the wind structure (assuming that it remained constant at the LMT spontaneous emission height) might have caused the brightness asymmetry in the form of a semi-ellipse (see Figure 4, bottom row). The brightest part of the meteor trail corresponds to the southward movement opposite to the incoming wind stream. January 23 and November 12, 2018 events Figure 7 shows fragments of images of meteor entry into Earth's atmosphere and LMT recorded by the GPhO camera in the $557.7 \mathrm{~nm}$ emission near the eastern horizon on January 23, 2018.

The time of observation of the meteor trail was $\sim 20$ min. The projection of velocity of the meteor trail was $\sim 34-40 \mathrm{~m} / \mathrm{s}$ (for a height of $90 \mathrm{~km}$ ). Unfortunately, entry of this meteor into Earth's atmosphere did not fall into the field of view of the SSO camera. There were, therefore, no basic observations and it was impossible to assess total velocities for this event. As for the November 18, 2017 event, the ionosonde recorded LMT similar to that shown in Figure 5. Projections of velocity of LMT regions estimated from the upper and lower edges of horizontal trails in ionograms were $\sim 50-80 \mathrm{~m} / \mathrm{s}$. The duration of the ionization trails in both the cases was $\sim 7-8 \mathrm{~min}$.

A quasi-circular LMT was also recorded on November 12,2018 by three GPhO cameras. This phenomenon was not recorded at SSO because of weather conditions. The observation time of this LMT according to data from different GPhO cameras was $\sim 15-18 \mathrm{~min}$.

Space-time structure of LMT. Generally, the spacetime structure and dynamics of LMT after a meteor impact are formed under the action of winds at meteor

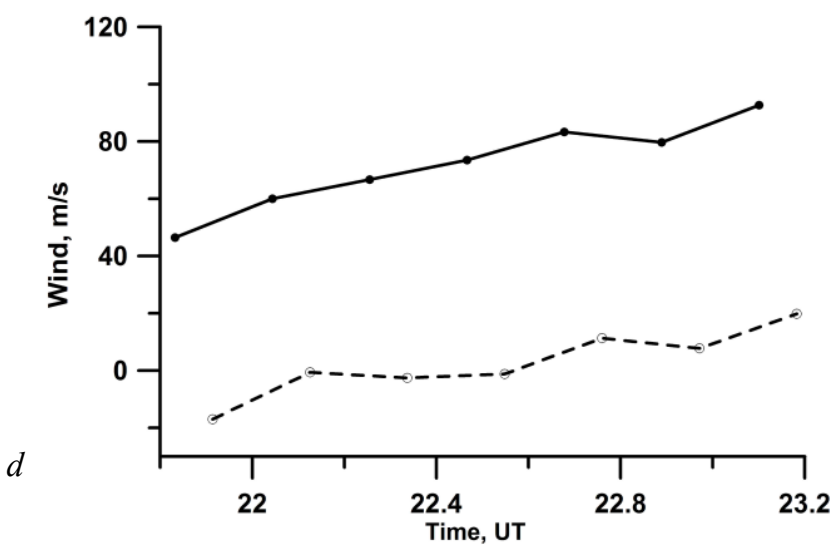

Figure 6. Meridional (solid line) and zonal (da $c$ line) winds as derived from observations made with the GPhO FabryPerot interferometer in the $557.7 \mathrm{~nm}$ [OI] line on November 18, 2017 between 22-23 UT
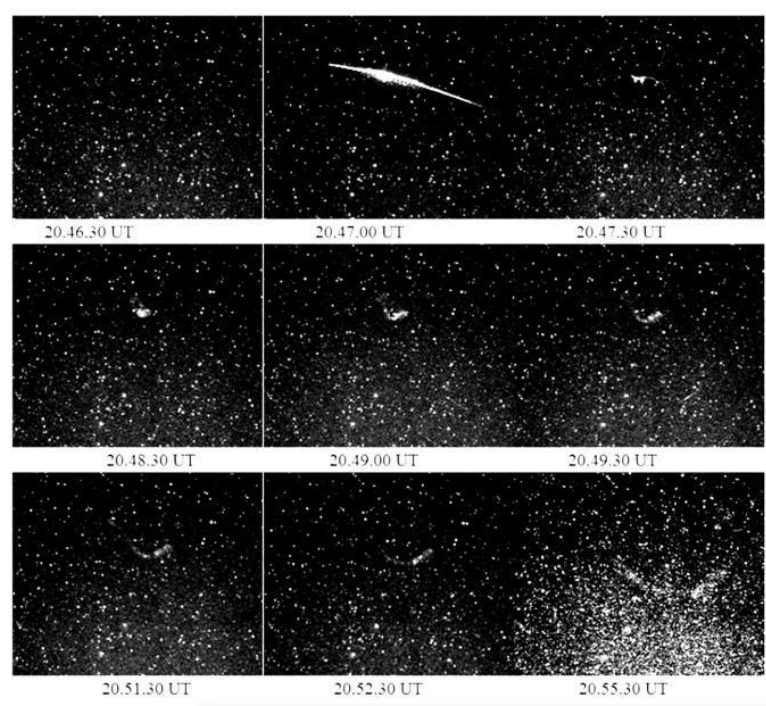

Figure 7. Fragments of images of meteor entry into Earth's atmosphere and a long-lived meteor trail recorded on January 23, 2018 (in the last frame, the contrast is set high)

heights [Smirnov, 1994]. Dynamics of the LMT recorded on November 16, 2017 correlates well with this interpretation. At the same time, the interpretation of space-time structures of the LMTs recorded on November 18, 2017, January 12 and 23, 2018 presents some difficulties. This is primarily associated with preservation of luminous expanding trails having almost oval shapes virtually throughout the observation time. These LMT structures formally resemble stable soliton waves. Zinn and Drummond [2007] attribute the LMT formation in the form of unusual circular rings on scales of hundreds of meters to twisting by vortex vertical winds. In the events analyzed, space structures remain unchanged on scales of tens of kilometers.

Observed velocities and possible mechanisms of motion. The most comprehensive data on velocities has been obtained for the November 18, 2017 event. The bow region of the meteor trail loop in the interval from 22:25 UT to $22: 47$ UT as inferred from optical data moved at a constant velocity of $\sim 320 \mathrm{~m} / \mathrm{s}$, which is by 20-30\% higher than the calculated velocity of sound at a given height in the standard-atmosphere model. As derived from radio sounding data, projections of LMT velocity estimated from upper and lower edges of horizontal trails in ionograms are $\sim 25-50 \mathrm{~m} / \mathrm{s}$.

Propagation of the disturbances associated with ejections and explosions of meteoric material in the upper atmosphere is known to be due to diffusion or propagation of shock and acoustic gravity waves (see, e.g., [Zeldovich, Raiser, 2008; Platov et al., 2013]).

Diffusion in its classical version occurs in the atmosphere at a molecular level and becomes significant as a transfer process only in the thermosphere. At lower heights, the main transfer process is associated with motion of certain volumes of air and accordingly with turbulent diffusion [Brasseur, Solomon, 1984]. Order of the maximum turbulent diffusivity $D_{\mathrm{t}}$ is $\sim 10^{2}-10^{3} \mathrm{~m}^{2} / \mathrm{s}$ [Banks, Kockarts, 1973; Gaigerov, 1986 ]. The characteristic dependence of diffusion expansion is usually described by the expression [Kashcheev et al., 1967] 


$$
r=(4 D t)^{1 / 2},
$$

where $D$ is the diffusivity.

For the November 18, 2017 event with the observation time of the optical trail of $40 \mathrm{~min}$, Expression (1) with maximum $D_{\mathrm{t}} \sim 10^{3} \mathrm{~m}^{2} / \mathrm{s}$ gives a characteristic size of diffusion expansion of $\sim 3 \mathrm{~km}$, which is substantially less than the observed values.

Platov et al. [2013] have examined specific optical phenomena in the upper atmosphere associated with launches of powerful solid-propellant rockets: development of spherically symmetrical gas-dust formations having the shape of an expanding torus in the plane of the sky. To interpret the observed time dependences of velocities and radius of spherical formations, the authors study the approximation of strong explosion in a gaseous medium derived from the self-similar solution [Sedov, 1987]. In this approximation, the time dependence of shock wave radius $r$ and velocity $v$ for a spherically symmetric case have the form [Sedov, 1987]

$$
r=(E / p)^{1 / 5} t^{2 / 5}, v=2 / 5(E / p)^{1 / 5} t^{-3 / 5},
$$

where $E$ is the energy released in the explosion, $p$ is the initial gas density.

Note that the observed velocities of LMTs, as derived from both optical and radio sounding data, for the November 18, 2017 event remain constant during their recording times as compared to the dependence in (2).

Platov et al. [2013] believe that shock wave propagation may occur with drag of particles of the condensed phase of fuel components in the first seconds of their spread, almost all the material concentrated in a relatively narrow layer behind the shock wave front. Grigoryan et al. [2013] also indicate a possible formation of a narrow layer. "... passage of fireballs of both comet and asteroid origin through Earth's atmosphere is followed by their intense aerodynamic destruction and transverse spreading under the action of the pressure gradient on the front surface of the fireball. These processes culminate with abrupt aerodynamic deceleration and instantaneous conversion of kinetic energy of the fireball into thermal energy of fireball and atmosphere particles in a relatively thin layer in the explosion zone with generation of high temperatures and shock wave there". Platov et al. [2003] have examined deceleration conditions of large particles when they move in the upper atmosphere in terms of rocket emissions. In particular, they have found that for particles with the typical size of $1 \mu \mathrm{m}$ the deceleration length may be as great as tens of kilometers or more at heights above $120 \mathrm{~km}$.

Some similar effects also arise during evolution of artificial plasma irregularities and during injection of plasma clouds into Earth's ionosphere when ambipolar diffusion and electromagnetic fields play a key role [Philipp et al., 1986]. In these experiments, the form of irregularities is determined by diffusion processes and motion in the crossed electric and magnetic fields, velocities being as high as $\sim 100 \mathrm{~m} / \mathrm{s}$. The recorded forms of irregularities are continuous spherical, ellipsoidal or cigar-shaped structures extended along the magnetic field, which differ from the expanding ring or toroidal formations we analyze [Platov et al., 2013].
Estimate the possible change in the meteoric speed for heights $\sim 70-120 \mathrm{~km}$ in case of its horizontal motion within the concept of [Platov et al., 2013]. For this purpose, use the main equation of meteor motion [Bronstein, 1981]

$$
M d V / d t=-\Gamma S p V^{2},(3)
$$

where $M$ is the meteoric mass, $V$ is its velocity, $\Gamma$ is the drag coefficient $(0.5 \leq \mathrm{G} \leq 1.0), S$ is the cross-section area (midsection) of the meteor, $p$ is the air density.

Then the change in the particle velocity

$$
V=V_{0} /\left(1+3 p V_{0} t /\left(4 p_{0} r\right)\right)=V_{0} /(1+K),
$$

where $K=3 p V_{0} t /\left(4 p_{0} r\right), p_{0}$ is the meteor density, $r$ is the meteor radius.

Obviously, the meteor speed should change when $K$ becomes comparable to 1 .

Table lists calculated values of $K$ for heights of 70, 80, 90 , and $120 \mathrm{~km}$ and different sizes of meteors $r$. When calculating $K$, we take $p_{0}=5 \mathrm{~g} / \mathrm{cm}^{3}$ (mean for stone and iron meteors), $V_{0}=50 \mathrm{~m} / \mathrm{s}$ (typical value of the measured LMT velocity), $t=10^{3} \mathrm{~s}$ (typical time of LMT observation). We have used values of $p$ from the standard model of Earth's atmosphere.

\begin{tabular}{|c|c|c|c|c|c|}
\hline $\begin{array}{c}\text { Height } \\
\mathrm{km}\end{array}$ & $1 \mu \mathrm{m}$ & $100 \mu \mathrm{m}$ & $1 \mathrm{~mm}$ & $2 \mathrm{~mm}$ & $10 \mathrm{~mm}$ \\
\hline 70 & 825 & 8.25 & 0.825 & $\mathbf{0 . 4 1}$ & $\mathbf{0 . 0 8 2 5}$ \\
\hline 80 & 203 & 2.03 & $\mathbf{0 . 2}$ & $\mathbf{0 . 1}$ & $\mathbf{0 . 0 2}$ \\
\hline 90 & 37.5 & $\mathbf{0 . 3 7 5}$ & $\mathbf{0 . 0 3 7 5}$ & $\mathbf{0 . 0 1 8}$ & $\mathbf{0 . 0 0 3 7 5}$ \\
\hline 120 & $\mathbf{0 . 4 9}$ & $\mathbf{0 . 0 0 4 9}$ & $\mathbf{0 . 0 0 0 4 9}$ & $\mathbf{0 . 0 0 0 2 4 5}$ & $\mathbf{0 . 0 0 0 0 4 9}$ \\
\hline
\end{tabular}

From the $K$ values listed in Table it follows that the mode of meteor particle motion without deceleration on a characteristic time scale of $\sim 10^{3} \mathrm{~s}$ at $70-90 \mathrm{~km}$ can be realized only for sufficiently large particles greater than $100 \mu \mathrm{m}$ with a high density of meteoric matter (these values are highlighted in bold in Table). Note that the results obtained for a fraction of $\sim 1 \mu \mathrm{m}$ particles are consistent with the conclusions drawn by Platov et al. [2003]. In this case, the concept formulated in [Platov et al., 2013] for the interpretation of spherically symmetric gas-dust formations of toroidal structure associated with launches of solid-propellant ballistic rockets may also be applied to the observable LMTs we discuss. Differences may be related to heights of occurrence of these formations, chemical composition, and sizes of associated particles.

Optical observations of velocities of luminous LMT regions $(\sim 320 \mathrm{~m} / \mathrm{s})$ during the November 18, 2017 event indicate a developed low-intensity shock wave. It is known that a weak shock wave moves through the undisturbed gas at a velocity very close to the velocity of sound, i.e. it is almost similar to the acoustic compression wave [Landau, Lifshits, 1986; Zeldovich, Raiser, 2008]. In this case, in the zone farthest from the place of the formation of the shock wave, the shock wave velocity under certain conditions (e.g., at insignificant dissipation in the case of weak shock wave) may vary slightly, asymptotically tending to the velocity of sound (see, 
e.g., [Pinaev et al., 2000]. This property of the weak shock wave as well as motion of the meteor particle without deceleration having significantly large momentum compared to medium particles can explain the almost constant velocity of disturbances in the November 18, 2017 event, using optical data.

In this regard, the use of only the above observations does not allow us to unambiguously explain the mechanism of formation and propagation of soliton-type LMT. Let us analyze two mechanisms of formation of spherically symmetric LMTs in explosions of sufficiently large meteors (fireballs). In the first case, an explosion produces a shock wave that can give a momentum to spreading particles of meteoric material. Almost all the material is concentrated in a thin layer, sustaining a certain initial velocity and moving independently of the shock wave. In the second case, the explosion itself sets the initial velocity of meteor particles, which then propagate in the form of a relatively fine spherically symmetric structure. At some heights and sizes, particles can move in horizontal directions in the atmosphere without velocity attenuation for a long time $\left(10^{3} \mathrm{~s}\right.$ and more), over tens to hundreds of kilometers. In the second case, the decisive role is played by a weak low-dissipative shock wave moving at a transonic speed.

For the November 18, 2017 event, the LMT velocities calculated from optical and radiophysical data vary considerably, as do times of recording and characteristic scales of disturbed regions. We can assume that LMT formed simultaneously with the optical one, but expanded at significantly lower speeds $(\sim 25-50 \mathrm{~m} / \mathrm{s})$. The initial forms of ionization and optical trails formed simultaneously immediately after the meteor explosion and were similar. The subsequent difference between LMT propagation velocities obtained by radiophysical and optical methods can be attributed to different mechanisms of propagation of neutral (optical trail) and charged (ionization trail) components of the initial disturbed region.

Mechanisms of LMT glow. The literature discusses several possible mechanisms of long-term LMT glow. In addition to ionization trails, dust meteor trails can be observed which form after the passage of bright fireballs, followed by meteor precipitation [Babadzhanov, 1987]. The dust trails can be seen due to sunlight scattering during daylight or twilight hours. Heights of formation of the dust trails are lower than those of ionization trails, most often they form at heights of $60 \mathrm{~km}$ and below. After the passage of fireballs, we can see a dust trail that can persist for hours in twilight or moonlight [Astapovich, 1958]. Mechanisms of LMT glow associated with emissions of atmospheric components in the $\mathrm{Na}, \mathrm{OH}$, and $\mathrm{O}$ lines $(557.7$ and $630 \mathrm{~nm})$ are also discussed (refer, e.g., to [Clemesha et al., 2001, Kelley et al., 2000], etc.).

The November 16, 2017 event observed before astronomical twilight (angular heights of the Sun $-26^{\circ} \div-$ $\left.17^{\circ}\right)$ under conditions of the low rising Moon $\left(-2^{\circ} \div 6^{\circ}\right.$ heights, $2.4 \%$ Moon phase, the new Moon is on November 18). The November 18, 2017 event was observed in astronomical twilight (angular heights of the
Sun $-19^{\circ} \div-14^{\circ}$ ) under conditions of rising Moon $\left(2^{\circ} \div 10^{\circ}\right.$ heights, $0.4 \%$ Moon phase). The November 23, 2018 event was observed in the nighttime moonless period (angular heights of the Moon $-32^{\circ} \div-34^{\circ}$ ). In this regard, in the events analyzed, in addition to twilight or moonlight scattering by meteoric material, we should probably consider mechanisms of long-term glow related to the glow of both meteoric material and atmospheric components.

\section{CONCLUSIONS}

The data on long-lived ( $\sim 20-40 \mathrm{~min})$ meteor trails we presented has been obtained from the study of regular and irregular variations in Earth's upper atmosphere emission. In addition to the example of ordinary LMT developed from the original linear meteor trail under the action of winds, we have presented the results of observations of soliton-type meteor trails expanding over large (up to $400 \mathrm{~km}$ ) distances at transonic speeds. The radio sounding data indicates the presence of $\sim 7-8 \mathrm{~min}$ ionization trails occurring simultaneously with the optical meteor trails. In this case, quite an extended region of the neutral atmosphere and ionosphere can be disturbed. It is likely that the greatest difficulty in interpreting the source of the described optical and ionospheric disturbances arises when recording equipment misses meteor entry into the atmosphere.

We have analyzed possible mechanisms of the formation of soliton type meteor trails and conditions favorable for quasi-horizontal propagation of disturbances over large distances without velocity attenuation. Estimated maximum velocities under turbulent diffusion at heights of meteor trail emission do not allow us to consider this process responsible for the observed phenomenon. We have examined propagation of meteor particles of size from $1 \mu \mathrm{m}$ to $10 \mathrm{~mm}$ having initial transonic speeds for heights $\sim 70-120 \mathrm{~km}$ in case of their horizontal motion. We assume that the meteor particles reach transonic speeds due to meteor explosion. We have shown that the mode of meteor particle motion without deceleration on a characteristic time scale of $\sim 10^{3} \mathrm{~s}$ at $70-90 \mathrm{~km}$ can be realized only for sufficiently large particles over $100 \mu \mathrm{m}$. We do not exclude the case of weak shock wave propagation at transonic speeds either.

The long-term glow of meteor trails and features of its spectra may be caused by the glow of both meteoric material and atmospheric components.

Due to the relatively rare observation of this phenomenon, we can assume that such phenomena can be driven by sufficiently large meteors having a specific composition, size, and speed. To detect and study such phenomena, we need high-sensitive optical and spectral equipment capable of recording the background airglow.

This work was supported by RFBR grant No. 17-0500492. Observations of Earth's upper atmosphere emission was performed with budgetary funding of Basic Research program II.16. Astrometric processing of observations of meteor trails was carried out under Project No. 3.9620.2017/BCh within the basic part of the state task. This work is based on data from the optical complex of the Center for Common Use "Angara". 


\section{REFERENCES}

Astapovich I.S. Meteornye yavleniya $v$ atmosfere Zemli [Meteor phenomena in Earth's atmosphere]. Moscow, State Publishing House of Physical and Mathematical Literature. 1958. 650 p. (In Russian).

Avakyan S.V., Evlashin LS, Kovalenok V.V., Lazarev A.I., Titov V.G. Nablyudeniya polyarnikh siyanii iz kosmosa [Aurora Observations from Space]. Leningrad, Gydrometeoizdat, 1991. 300 p. (In Russian).

Babadzhanov P.B. Meteory i ikh nablyudeniya [Meteors and their observation]. Moscow, Nauka Publ., 1987. 176 p. (In Russian).

Banks P.M., Kockarts G. Aeronomy. Part B. 1973. Academic Press. New York and London, 1973. 355 p.

Beletsky A.B., Gress O.G., Mikhalev A.V., Shalin A.Yu., Potapov A.S. Nightglow behavior during the 16-18 November 2001 passage of the Leonids meteor stream. Adv. Space Res. 2004, vol. 33, iss. 9, pp. 1486-1490. DOI: 10.1016/ j.asr.2003.05.002.

Brasseur G.P., Solomon S. Aeronomy of the Middle Atmosphere (Chemistry and Physics of the Stratosphere and Mesosphere). D. Reidel Publishing Company, Dordrecht, Holland, 1984. 441 p. DOI: 10.1002/qj.49711146917.

Bronstein V.A. Fizika meteornykh yavlenii [Physics of meteor phenomena]. Moscow, Nauka Publ., 1981. 416 p. (In Russian).

Clemesha B.R., F. de Medeiros A., Gobbi D., Takahashi H., Batista P.P., Taylor M.J. Multiple wavelength optical observations of a long-lived meteor trail. Geophys. Res. Lett. 2001, vol. 28, no. 14, pp. 2779-2782. DOI: 10.1029/ 2000GL012605.

Gaigerov S.S. Issledovanie srednei atmosfery [The study of the middle atmosphere (meteorology of 20-120 km altitudes)]. Abstract J. All-Russian Institute of Scientific and Technical Information. Ser. Geomagnetism and High Layers of the Atmosphere. Moscow, 1986, vol. 8. 156 p. (In Russian).

Grigoryan S.S., Ibodov F.S., Ibadov S.I. Physical mechanism of Chelyabinsk superbolide explosion. Solar System Res. 2013, vol. 47, no. 4, pp. 268-274. DOI: 10.1134/S0038094613040151.

Grigoryev G.I. Acoustic-gravity waves in the Earth's atmosphere (Review) // Izvestiya vuzov. Radiofizika [Radiophysics and Quantum Electronics]. 1999, vol. XLII, no. 1, pp. 3-24. (In Russian).

Kashcheev B.L., Lebedinets V.N., Lagutin M.F. Meteornye yavleniya $v$ atmosfere Zemli [Meteor phenomena in Earth's atmosphere]. Moscow, Nauka Publ., 1967. 260 p. (In Russian).

Kelley M.C., Gardner C., Drummond J., Armstrong T., Liu A., Chu X., et al. First observations of long-lived meteor trains with resonance lidar and other optical instruments. Geophys. Res. Lett. 2000, vol. 27, no. 13, pp. 1811-1814. DOI: 10.1029/1999GL011175.

Landau, L.D, Lifshits, E.M. Gidrodinamika Teoreticheskaya fizika [Hydrodynamics. Theoretical Physics] The 3rd Edition, vol. VI. Moscow, Nauka Publ., 1986. 736 p. (In Russian).

Mikhalev A.V. Midlatitude radiation of the Earth's upper atmosphere under heliogeophysical disturbances. Solnechnozemnaya fizika. [Solar-Terrestrial Physics]. 2011, iss. 17, pp. 179-183. (In Russian).
Mikhalev A.V., Beletsky A.B., Vasilyev R.V., Eselevich M.V., Ivanov K.I., Komarova E.S., Podlesny A.V., Podlesny S.V., Syrenova T.E. Long-lived meteor trails, formed by the explosions of large meteoroids. XVI Vserossiiskaya otkrytaya konferentsiya «Sovremennye problemy distantsionnogo zondirovaniya Zemli iz kosmosa [The $16^{\text {th }}$ All-Russian Open Conference "Modern Problems of Remote Sensing of Earth from Space. Moscow, IKI RAS, November 12-16, 2018. Abstracts. P. 476. (In Russian). http://smiswww.iki. rssi.ru/d33_conf/thesisshow.aspx?page $=153$ \& thesis $=6651$.

Philipp N.D, Oraevsky V.N., Blaunshteyn N.Sh., Ruzhin Y.Ya. Evolyutsiya iskusstvennykh plazmennykh neodnorodnostei $v$ ionosfere Zemli. The Evolution of Artificial Plasma Inhomogeneities in Earth's Ionosphere. Kishinev, Shtiintsa Publ., 1986. 246 p. (In Russian).

Pinaev A.V., Kuzavov V.T., Kedrinsky V.K. The structure of shock waves in the near zone in the explosion of space charges in the air. Prikladnaya mekhanika i tekhnicheskaya fizika [Applied Mechanics and Technical Physics]. 2000, vol. 41, no. 5, pp. 81-90. (In Russian).

Platov Yu.V., Kulikova G.N., Chernouss S.A. Classification of gas-dust structures in the upper atmosphere associated with exhausts of rocket-engine combustion products. Space Res. 2003, vol. 41, no. 2, pp. 153-158.

Platov Yu.V., Chernouss S.A., Alpatov V.V. Features of optical phenomena associated with launches of solidpropellant ballistic missiles. Geomagnetizm $i$ aeronomiya. [Geomagnetism and Aeronomy]. 2013, vol. 53, no. 2, pp. 198203. DOI: $10.1134 / \mathrm{S} 0016793213010155$.

Sedov L.I. Metody podobiya i razmernosti v mekhanike. [Methods of similarity and dimension in mechanics]. Moscow, Nauka Publ., 1987. 430 p. (In Russian).

Silber Elizabeth A., Boslough Mark, Hocking Wayne K., Gritsevich Maria, Whitaker Rodney W. Physics of meteor generated shock waves in the Earth's atmosphere - A review. Advances in Space Research. Issue 3, 1 August 2018, Pages 489-532. DOI: 10.1016/j.asr.2018.05.010

Smirnov V.A. Spektry kratkovremennykh atmosfernykh svetovykh yavlenii: Meteory. [Spectra of short-term atmospheric light phenomena: Meteors]. Moscow, Fizmatlit Publ., 1994. 208 p. (In Russian).

Zeldovich Ya.B., Raiser Yu.P. Fizika udarnykh voln $i$ vysokotemperaturnykh yavlenii [Physics of shock waves and high-temperature hydrodynamic phenomena]. $3^{\text {rd }}$ Edition. Moscow, Fizmatlit Publ., 2008. 656 p. (In Russian).

Zinn J., Drummond J. Formation of parallel meteor trail pairs as associated with their buoyant rise. Adv. Space Res. 2007, vol. 39, pp. 555-561. DOI: 10.1016/j.asr.2006.12.007.

URL: http://atmos.iszf.irk.ru/ru/data/keo

URL: http://atmos.iszf.irk.ru/ru/data/color

URL: http://atmos.iszf.irk.ru/ru/data/spectr

URL: http://atmos.iszf.irk.ru/ru/data/sati2

URL: http://atmos.iszf.irk.ru/ru/data/fpi

URL: http://dep1.iszf.irk.ru/CHIRP_ionogrames

How to cite this article

A.V. Mikhalev, A.B. Beletsky, R.V. Vasilyev et al. Long-lived meteor trails. Solar-Terrestrial Physics. 2019. Vol. 5. Iss. 3. P. 109-116. DOI: 10.12737/stp-53201913 